\title{
ANA CRISTINA CESAR: O DEVIR DE UM CORPO
}

André Luîs de Araújo*

RESUMO:

Compreender o fazer poético de Ana Cristina é entrar teoricamente em seu mundo, sua dinâmica, pelo viés da poesia.

$E$, tomando-a por inteiro, acompanhar a velocidade de sua passagem, sua performance corpo-voz, enquanto disseca suas alucinações, gozos e anseios em busca da palavra múltipla, abstraindo a morte dia a dia.

PALAVRAS-CHAVE: corpo, voz, devir, ironia, morte.

Se a tentativa de delimitar as linhas de força que caracterizam a poesia de Ana Cristina Cesar é um risco, cumpre encontrar um meio de ter acesso a esse objeto de análise sem, contudo, descaracterizá-10. Uma vez que qualquer demarcação envolve obrigatoriamente o reconhecimento de uma historicidade, de limites; mais que demarcá-1os, é necessário cartografá-los em sua refração, em sua fluidez.

Ana convida, passa o ponto e entrega as luvas a quem se atrever. No entanto, adverte: "Não sou personagem do seu livro e nem que você queira não me recorta no horizonte teórico da década passada" (A teus pés, p. 12). Corrobora o que diz Sussekind (1985: 9): "Quem se encontra "trancado" em certo período histórico, em determinadas amarras discursivas, dificilmente consegue enxergar esta "casa de vidro" com olhos diferentes daqueles que suas próprias circunstâncias biográficogeracionais the emprestaram."

Assumir-1he o ponto e calçar-1he as luvas seria desmesurada presunção. Entretanto, investigar-1he o contexto histórico e as circunstâncias geradoras de sua poesia, já forma parte do respeito a essas advertências e do cuidado teórico no

* Mestre em Letras: Literatura e Expressão da Alteridade (Área de concentração: Teoria da Literatura), 2004. 


\section{EMTESE}

Belo Horizonte, v. 9, p. I-28I, dez. 2005

manuseio de sua obra, indo buscá-la na efervescência em que começa a despontar, tendo como pano de fundo os anos de repressão política no Brasil.

Dessa forma, apesar de gerada na "marginalidade" dos anos 70, Ana Cristina imprime a seu verso um caráter universal, cosmopolita. Se o mundo é a sua casa e todos os lugares são seus, seu dizer é atemporal, ANAcrônico, meteórico de tão rápido, surreal de tão informe, complexo de tão simples, vivo de tão morto, registrando cada fato e acontecimento numa única frase sem, contudo, esgotá-1o.

É assim que sua poesia deflagra o fascínio pelo poder terapêutico das cartas, diários íntimos e o prazer proibido de parecer espiar a intimidade alheia pelo buraco da fechadura. Atrevida, mas sempre muito elegante, inaugura um espaço particular, onde não há diferença entre poesia e prosa, dramático e irônico, culto e emocional, cerebral e sensivel.

E é justamente nesse espaço que faz ganhar força uma poesia que se constitui de todos e de nenhum, porque Ana nunca traz respostas prontas, não tem fórmulas, não tem apegos. Quer construir, ousar, mover-se em direção da vida ou da morte, indo além, chegando ao ponto onde talvez ninguém tenha chegado.

Cria, por isso, novas rotas no tecido literário, promovendo com seu corpo e sua voz um esgarçamento de possibilidades discursivas. Não quantifica coisa alguma, não se preocupa com formalidades, nem com a fluidez de nada. Desprovida de tudo e acompanhada do olhar atento que vai sempre reaprendendo seu devir, sua multiplicidade, suas transformações, sua dificuldade em explicar-se por meio de teorias esquemáticas, dogmáticas, estruturadas demais; Ana é rizoma, fascículo, linha de fuga, reterritorialização, platô...

Assim, não há como compreendê-la se não se entrar em seu jogo, em sua vibração, se não se beber, também, da fonte de Foucault, Blanchot, Deleuze e Guattari e, dessa forma, tornar-se apto, com ela, a restituir o que falta aos olhares; tangenciar o que o olho vê; especular, anunciar, denunciar os sistemas molares da sociedade; multiplicar os focos e os pontos de vista.

Como um quebra-cabeças, sua poesia começa, então, a mostrar formas e a reinventá-1as, a construí-1as e a redimensioná-1as incessantemente. É um adestramento de si, na recomposição dos cenários voláteis da existência medíocre de cada ser que 
só se compreenderá e abandonará sua mediocridade se se aceitar na condição de devir, para sobreviver, e gerar, e gerir, e reproduzir suas subjetividades.

Desse modo, encontra-se aberto o campo para o diálogo com o corpo, seu sexo, suas escolhas, suas condutas. Tudo reverbera e o corpo não prende nada. Libera toda substância, toda poesia e o utiliza como veículo. 0 corpo passa e não é como cadáver que ele se inscreve, mas é na materialização da linguagem, nos movimentos e na performance, no natural e no sobrenatural, nas vísceras, nos humores, nos nervos, a fim de recompor o êxtase de preencher o vazio com palavras, também elas, dotadas de corpo e voz.

Consciente da importância conferida à própria experiência corporal da escrita e da fala, Ana exorta a dimensão física de toda e qualquer atividade humana a ultrapassar-se, intensificando a consciência através de manifestações orgânicas. Lançada a identidade a seu ponto de fuga, o que resta é um princípio de mutação permanente a comandar a percepção do sensivel.

Encantada com 0 arrojo da modernidade, Ana traduz em poesia o valor heurístico de pensar sempre de outro modo, subvertendo a indolência e o sentido das ações idealistas, de tal modo que, quando não mais tiver corpo físico com o qual falar, assumirá outras tantas variadas formas para encontrar sua palavra, à medida que cede sua voz aos demais.

Em vista disso, pronunciadas ou escritas, suas palavras vão ganhando corpo, participando de um processo cada vez mais amplo, operando sobre uma situação que altera e engaja de algum modo os corpos dos participantes. Promovem um litúrgico mutualismo, segundo Paul Zumthor (1993), em que todos os sentidos participam da trama da comunicação. E como acenos da fala ou caminhos do pensamento abertos na linguagem instigam a travessia dos campos semióticos em que estão inseridas, provocando a demolição de zonas fronteiriças e acionando vários mecanismos de leitura e interpretação, impedindo um fechamento e provocando múltiplas significações.

Os "corpos" das palavras colidem, copulam, produzem efeitos inéditos, para lá do imaginado, vão buscar a poesia em seus lugares insólitos. Do corpo à voz ou da voz ao corpo, ganham representação no sentido artístico, imagético ou discursivo.

E o gesto introduz a noção de performance, revelando que o corpo e a voz guardam estreita relação no momento de fixar e compor os sentidos; não deixando 


\section{EMTESE}

Belo Horizonte, v. 9, p. I-28I, dez. 2005

dúvida de que o que deve ter favorecido a difusão da escritura em todos os seus aspectos é a estreita relação mantida entre corpo e voz.

Confronta-se aí a capacidade que o gesto tem de decodificar, de se inscrever no âmbito da linguagem, de se expandir e evocar o discurso sem palavras, fixando e compondo os múltiplos sentidos advindos da ironia dessa correspondência sedutora e reveladora de inúmeras associações.

A existência dessa ironia e, por que não, a ironia dessa existência configuram, desde já, uma tensão com os ligamentos da essência que aciona, por conseguinte, um discurso irônico insurgente, mordaz, uma vez que, se de um lado, a modernidade insiste em um apagamento iminente do sujeito, em uma tentativa de eliminação do corpo e uma virtualização crescente, uma excessiva desmaterialização, a fobia do corpo a corpo; de outro, a proposta é exatamente o contrário.

Atuando contra essa desmaterialização, Ana Cristina Cesar instabiliza esse "terreno pacífico" onde nos constituímos, dando voz a um pensamento que articula os pontos em que a vida carrega a morte e se nutre dela, porque libera um sujeito que aprendeu a pensar problematicamente e faz do corpo ferramenta de expressão.

Fomenta um sujeito habitado pela linguagem, atravessado por raios, fios, vozes, discursos e em cujo corpo tudo parece pronunciar-se, tudo parece participar num esforço muscular considerável, quando o ofício é a escritura.

0 estatuto da voz, como se vê, está para além do meramente vocal, audível, mensurável, gráfico. É mais: é performance, é toque, é gestualidade, é víscera, é corpo, é materialidade. É a natureza fluídica do som, do movimento e dos dois atrelados um ao outro, numa dinâmica que comunica a vida que não esgota as capacidades do corpo, mesmo inerte, quando não existe o "sopro" que testemunhe sua ação.

Ana Cristina pactua com um sistema que antes de produzir cegueira ou estranhamento dota-nos de novas sensibilidades para aguçar nossa percepção de mundo. Percebe a linguagem do ponto de vista da variedade, das injunções de suas partes: letra, sílaba, conectivo, articulação, nome, verbo, flexão, frase. E, arriscando um pouco mais, incita-nos a ler a partir do corpo e da voz, dando conta, ainda, das vozes dentro da letra, das vozes dentro da voz vindas dos fundos das 
cavernas, dos músculos, das mucosas, das cartilagens. Vozes que nos fazem ouvir um corpo que, freqüentemente, não tem nome, não tem personalidade, mas que, mesmo assim, é uma materialidade repleta de significado.

Essa materialidade é o que vai eclodir a emergência de novas práticas sociais e estéticas em todos os domínios, é o que vai permitir o universo de referência das novas práticas discursivas, dos novos territórios existenciais coletivos, dos fragmentos virulentos de enunciação, conforme Guattari (1992: 33): "A única finalidade aceitável das atividades humanas é a produção de uma subjetividade que enriqueça de modo contínuo sua relação com o mundo".

É o que Ana Cristina propõe. Quer abrir para o virtual e para a processualidade criativa, quer um engajamento ético-estético enunciativo, uma forma de ser para além, um engendramento de novos campos de possível, foco constitutivo de uma constelação de universos de referência incorporais. Ser não apenas para si, mas para toda a alteridade do cosmos.

É a arte da performance liberando o instante, reinventando o corpo, receptivo às intensidades não-discursivas. Esvaziando a fala porque esta já passou pelo crivo de semiologias escriturais ancoradas na ordem da lei, do controle dos fatos, gestos e sentimentos. Fazendo proliferar não apenas formas, mas modalidades de ser, a busca de focos enunciativos e novas clivagens entre outros dentros e outros foras.

Uma oposição entre o oral e o escritural não me pareceria mais pertinente [...] passar da voz do discurso interior a uma presença a si, a formas radicalmente mutantes de subjetividade. Subjetividade do fora, subjetividade de amplidão que, longe de temer a finitude, a experiência de vida, de dor, de desejo e de morte, acolhe-as. (Ibidem: 114)

Ana brinca com o ponto limite, na tangente da finitude. Finitude existencial que não aceita apenas a morte e a vida em seu caráter de subjugação, mas que não cessa de intensificá-las. Faz da morte uma potência ativa, ao invés de uma maldição. Propõe sempre o descentramento estético dos pontos de vista, toda multiplicação polifônica dos componentes de expressão, porque passam pelo requisito de uma desconstrução das estruturas e dos códigos em vigor.

Assim, Ana Cristina faz ver que com o material das palavras, o homem constrói um mundo de instituições e relações imateriais e toda expressão lingüística 


\section{EMTESE}

Belo Horizonte, v. 9, p. I-28I, dez. 2005

foi desenvolvida com base no mundo corporal apoiado na imaginação. A ironia começa a ser percebida, então, como a tensão de um ser que é ao mesmo tempo corpo, espírito e matéria, infinitude e contingência. Essa tensão trata de dar sentido ao mundo material, a partir do corporal, como expressão do sentido do mundo gerado na história individual de cada ser.

A ironia da existência humana está irremediavelmente ancorada em um paradoxo e sua única forma de existência é ver-nos compelidos a utilizar categorias materiais e finitas como signo de algo que as ultrapassa. 0 ser humano encontra e escolhe, assim, no mundo e na linguagem, a forma de expressão que vai realizar o sentido de sua própria existência: o homem não é substância nem natureza, senão atividade e história.

0 sentimento trágico da vida é a ironia kierkegaardiana. Para o filósofo, como conclui Ramírez (1992), o sujeito se constitui como uma articulação paradoxal entre o finito e o infinito, 0 transcendente e o contingente. A ironia supõe a exigência existencial de conjugar duas realidades incomensuráveis. 0 ser humano só pode consumar sua humanidade assumindo o paradoxo de sua existência.

Trata-se, pois, de deixar irromper uma subjetividade que aprendeu a viver na experiência da catástrofe, dando uma nova medida ao ser humano: do fundo de nossa ignorância animal pode nascer uma sensibilidade soberana que permita vislumbrar o "extremo do possível" no qual nada conta além do instante vivido. Faz elevar, assim, no próprio instante uma forma de vida no nível do pior, ou seja, mais vale viver à altura do trágico do que gemer e não poder suportar nem mesmo a idéia de sua existência.

Despossuído de tudo, o ser poético - humano, talvez - torna-se, enfim, uma presença silenciosa que nenhum poder pode suprimir. É a vida e a morte comunicandose para continuar sendo, indefinidamente, uma na outra. É a exigência de ultrapassar a vontade própria, de fazer convergir o desejo individual com a necessidade pura, que remete ao devir e ao sentido de todos os valores ou, mais precisamente, a um movimento constante. Primeiramente, desagregador - com a possibilidade da destruição do homem - para, em seguida, iluminar outras possibilidades discursivas.

Dessa forma, as considerações de Bataille e Blanchot lançam luz sobre 0 caráter particular da existência tão afinada à poética de Ana C., uma vez que não 
há limites para a destruição do homem e sua desfiguração só pode realizar-se enquanto um processo interminável, sem jamais alcançar um estágio definitivo e absoluto.

Outras novas possibilidades de leitura são dadas a situações anteriormente antagônicas, uma vez que se estabelecem relações de correspondência também entre os termos e não apenas a oposição antes pensada. (Morte-vida, por exemplo). Ana Cristina vem explorar, então, esse vasto campo em que as determinações contraditórias figuravam como o transtorno periódico para a existência dos homens, afirmando a instabilidade como forma de se apresentar uma reflexão: refazer o homem desrealizandoo, afim com a idéia de Bataille (Cf. Moraes, 2002), que diz que tudo exige em nós que a morte nos devaste.

Sua escrita transpõe a poética numa perspectiva corporal, carnal, visceral, ao mesmo tempo fina e sofisticada. Seus corpos inúmeros (matéria, voz, palavra, sexo, ironia...) abrem espaços à zona instrumental das sensações e do desenrolar das emoções. A estética de seus escritos eleva o questionamento da corporalidade, da noção de limites, das inquietudes. Não expõe meramente o corpo, a voz, o sexo, a morte; fala de nossas falências, de nosso padecer; disseca nossas experiências: decifra os gozos e as misérias através do sentimento, da devastação.

Ana Cristina encantou e desencantou com a modernidade e não deixou de afirmar o homem, seu corpo, sua voz, seu sexo, suas relações irônicas, sua vida enfim. Sinalizou que, para a modernidade, o dilaceramento do homem tornou-se a saída para permitir reencontrá-1o por inteiro, não mais na sua ilusória completude antropomórfica, mas em seu permanente inacabamento.

Recolocar questões de direito é o que faz em toda sua obra. 0 direito à vida e à morte, o direito às manifestações múltiplas e performáticas do corpo, da voz, do sexo. 0 direito de dispor do que se tem, do que se é, sempre em busca, sempre avançando, sempre devir, sempre movimento.

A figura do suicídio literário, então, emerge com a força necessária para se compreender as escolhas feitas pela subjetividade inscrita em seus poemas, dando-1he extraordinária credibilidade. É assim que se morre, supõe-se que haja algo forte, perigoso de tão verdadeiro. Ficamos com a visão tocante de infelicidade 


\section{EMTESE}

Belo Horizonte, v. 9, p. I-28I, dez. 2005

angustiada e intolerável em um primeiro momento, para depois despertar para o uso incondicional de suas atribuições, o direito de se dispor ou indispor livremente...

A relação irônica da vida tornada morte por meio da figura do "suicídio literário" aqui exposto teve como cuidado principal evitar a coincidência biográfica, uma vez que só aparentemente os textos de Ana nos fazem revelações entre o sujeito biográfico e o sujeito dos diários. Além disso, não se trata da transposição de pessoa real para imagem construída. Uma já se encontra refratada na outra e nessa fusão de facetas não há centro ou miolo a ser revelado. "0 manequim de dentro, reflexo do manequim de fora. Se você me olha bem, me vê também no meio do reflexo, de máquina na mão" (A teus pés, p. 98).

Cada vez fica mais clara e fluida nossa visão: é preciso ajustar o foco e não se esquecer da luva! Se há um ser representado num texto que pode se dizer autobiográfico, sua identidade é formada tanto pelas mediações da linguagem e da escritura literária quanto pela "personalidade" do autor, que é, ela mesma, também uma representação conceitual, conforme afirma Ana Cláudia Coutinho Viegas em seu livro Bliss \& Blue: segredos de Ana C. (1998). Calçando e descalçando as luvas, escrevendo ou inscrevendo-se o que nos importa analisar é a subjetividade literária antes de tudo.

ABSTRACT :

Understanding Ana Cristina's poetry making is theoretically coming into her world, her dynamics through poetry. And, it is also having her completely, following the speed of her passage, her body-voice performance, while detailing her hallucinations, delights and also anxiety in searching the multiple words, abstracting death day by day.

KEY WORDS: body, voice, changes, irony, death. 
BARTHES, Roland. O grão da voz. Entrevistas: 19621980. Trad. Teresa Meneses e Alexandre Melo. Lisboa: Edições 70, 1982.

.o óbvio e o obtuso: ensaios críticos III. Rio de Janeiro: Nova Fronteira, 1990.

- O prazer do texto. São Paulo: Perspectiva, 2002.

BLANCHOT, Maurice. O espaço literário. Trad. Álvaro Cabral. Rio de Janeiro: Rocco, 1987.

- O livro por vir. Trad. Maria Regina Louro.

Lisboa: Relógio D'Água, 1984.

- Michel Foucault - tel que je l'imagine. Paris: Fata Morgana, 1986.

- A parte do fogo. Trad. Ana Maria Scherer. Rio de Janeiro: Rocco, 1997.

- Pena de morte. Trad. Ana Maria de Alencar. Rio de Janeiro: Imago: 1991.

CESAR, Ana Cristina. Escritos no Rio. São Paulo: Brasiliense, 1993.

$\overline{19} \overline{9} \overline{3}$. - Inéditos e dispersos. São Paulo: Brasiliense, - A teus pés. São Paulo: Brasiliense, 1993.

DE MAN, Paul. El concepto de ironía. EUTOPÍAS, $2^{a}$ Época. Universidad de Valencia, 1999.

DELEUZE, Gilles. Foucault. Trad. Cláudia Sant'Anna Martins. São Paulo: Brasiliense, 1988.

DELEUZE, Gilles; GUATTARI, Félix. Rizoma: Introducción. México: Ediciones Coyoacán, 1996.

DERRIDA, Jacques. Gramatologia. São Paulo: Edusp/ Perspectiva, 1973.

FOUCAULT, Michel. História da sexualidade I: A vontade de saber. Trad. Maria Thereza da Costa Albuquerque e J. A. Guilhon Albuquerque. Rio de Janeiro: Graal, 1988.

- As palavras e as coisas. Trad. Salma Tannus Muchail. São Paulo: Martins Fontes, 1987.

- O pensamento do exterior. Trad. Nurimar Falci. São Paulo: Princípio, 1990.

- O que é um autor? Trad. António Fernandes Cascais e Eduardo Cordeiro. Lisboa: Veja, 1992.

- Nietzsche, Freud \& Marx. Theatrum Philosoficum. Trad. Jorge Lima Barreto. São Paulo: Princípio, 1987. $\overline{1977}$. La Vie des Hommes Infâmes. Les Cahiers du Chemin,

- Ditos e Escritos III. Estética: Literatura e Pintura, Música e Cinema. Trad. Inês Autran Dourado Barbosa. Rio de Janeiro: Forense Universitária, 2001. guATtARI, Félix. Caosmose. Um novo paradigma estético. Trad. Ana Lúcia de 01 iveira e Lúcia Cláudia Leão. Rio de Janeiro: Editora 34, 1992.

GUATTARI, Félix. Revolução molecular: pulsações políticas do desejo. São Paulo: Brasiliense, 1987. 
MACHADO, Roberto. Foucault, a filosofia e a literatura. Rio de Janeiro: Zahar, 2000.

MORAES, Eliane Robert. O corpo impossível. São Paulo: Il uminuras, 2002.

NUNES, Benedito. 0 esquecimento da fala. Folha de $S$. Paulo, São Paulo, 08 fev. 2003. Jornal de Resenhas.

RAMírez, José Luis. La existencia de la ironía como ironía de la existencia. In: Seminario de Antropología de la Conducta, Universidad de Verano, San Roque, Cádiz, 1992.

SUSSEKIND, Flora. Literatura e vida literária: polêmicas, diários e retratos. Rio de Janeiro: Jorge Zahar, 1985.

VASCONCELOS, Maurício Salles. Da superioridade da Literatura Anglo-Americana - Deleuze crítico literário? Revista de Estudos de Literatura. BH, v. 5, out. 1997.

VELASCO, Arnulfo Eduardo. La problemática de la desnudez: Intento de análisis de nuestra percepción de la corporeidad. Sincronía, verano 2000.

VELASCO, Francisco Diez de. Reflexiones transculturales sobre la muerte y el morir. Bitarte 17 (abri1, 1999), p. 53-66.

VIEGAS, Ana Cláudia Coutinho. Bliss \& Blue: segredos de Ana C. São Paulo: Annablume, 1998.

WISNIK, José Miguel. 0 som e o sentido. São Paulo: Companhia das Letras, 1999.

ZIZEK, Slavoj. ¿Por qué es la mujer un sīntoma del hombre? In: iGoza tu síntoma! Buenos Aires: Nueva Edición, 1992. p. 47-89.

ZUMTHOR, Paul. A letra e a voz. São Paulo: Companhia das Letras, 1993. 